\title{
Seasonal Variations in Groundwater Level and Salinity in Coastal Plain of Eastern China Influenced by Climate
}

\author{
Shao-feng Yan, ${ }^{1,2}$ Shuang-en Yu, ${ }^{1}$ Yu-bai Wu, ${ }^{1,2}$ De-feng Pan, ${ }^{3}$ \\ Dong-li She, ${ }^{1}$ and Jianzhong $\mathbf{J i}^{4}$ \\ ${ }^{1}$ Key Laboratory of Efficient Irrigation-Drainage and Agricultural Soil-Water Environment in Southern China, \\ Ministry of Education, College of Water Conservancy and Hydropower Engineering, Hohai University, Nanjing 210098, China \\ ${ }^{2}$ Jiangsu Water Conservancy Research Institute, Nanjing, Jiangsu 210017, China \\ ${ }^{3}$ Jiangsu Coastal Water Conservancy Research Institute, Dongtai, Jiangsu 224200, China \\ ${ }^{4}$ Water Conservancy Survey and Design Institute Co., Ltd, Huaian 223005, China
}

Correspondence should be addressed to Shao-feng Yan; shaofey@163.com and Shuang-en Yu; seyu@hhu.edu.cn

Received 3 August 2014; Revised 6 September 2014; Accepted 8 September 2014

Academic Editor: Jun Wu

Copyright (C) 2015 Shao-feng Yan et al. This is an open access article distributed under the Creative Commons Attribution License, which permits unrestricted use, distribution, and reproduction in any medium, provided the original work is properly cited.

\begin{abstract}
The coastline of China is approximately $18,000 \mathrm{~km}$ long. In most coastal cities, seawater intrusion is a serious threat to groundwater resources. Nine shallow monitoring wells were constructed to study the dynamics of shallow groundwater level and salinity in the coastal plain region of Jiangsu province, China. Results showed that precipitation, evaporation, and river stage affected the groundwater level in our study area. Positive correlations were observed among the groundwater level, precipitation, and river stage; then negative correlation existed between the groundwater level and evaporation. The influencing factors on the groundwater level were in the order precipitation $>$ river stage $>$ evaporation. Sufficient precipitation during the wet season diluted the groundwater salinity. After the dilution, between two continuous precipitation events, the groundwater salinity increased as the groundwater level decreased. During the dry season, the groundwater salinity rapidly increased and reached its peak in December. The groundwater salinity in December was 23 times higher than that in July. The groundwater level and salinity in this study were generally associated with the season. Climate factors led to fluctuation of groundwater levels and salinity during the wet season, and seawater intrusion increased the groundwater salinity during the dry season.
\end{abstract}

\section{Introduction}

Knowledge of hydrological processes (change of groundwater level, groundwater quality, and tidal level) in coastal aquifers is important because approximately 50 percent of the world population live in coastal zones, particularly in low-lying deltaic areas within $60 \mathrm{~km}$ of the shoreline [1]. Coastal aquifers typically serve as a major source of freshwater, such as drinking or irrigation water [2].

The groundwater level is a key parameter for evaluating spatial and temporal changes in groundwater environments [3]. The groundwater level is governed by various factors. Climate change, as reflected in precipitation and evaporation rates, influences the groundwater level fluctuation [4]. Chen et al. also found that climate trends have high correlations with groundwater level variations in southern Manitoba [5]. In plain areas, precipitation infiltration and evapotranspiration in the vertical direction are the major recharge and discharge processes of the water cycle [6]. In our study area, most of rainfall falls between July and October. Seasonal variation in climate is very obvious. So we focus on the influence of short-term seasonal variation in climate on groundwater level in this place. The impact of climate variability on groundwater levels can be investigated by analyzing the relationship between climate records and groundwater level fluctuations.

The groundwater salinity is an important groundwater quality indicator, which is controlled by the factors such as precipitation, evapotranspiration, mineralogy, type of aquifers, topography, and seawater intrusion [7]. Climate 
change and sea level rise exacerbated saltwater intrusion, thereby jeopardizing water use safety, especially during the dry season [8]. Saltwater intrusion can degrade water quality and reduce available water if insufficient freshwater are entering the groundwater system, and it became more serious than it was before, particularly in delta areas, because of climate change [8]. Saltwater intrusion occurred globally in more than 50 countries and regions, particularly North Africa, the Middle East, the Mediterranean, China, Mexico, and the Atlantic and Gulf Coasts of the United States, including Southern California $[9,10]$. Saltwater intrusion can negatively affect coastal ecosystems in terms of freshwater quality and the dynamics of plant community. Along with saltwater intrusion, salinization of the groundwater systems may affect agriculture and domestic and industrial water supplies [11]. Extensive researches were conducted worldwide to understand the mechanisms of saltwater intrusion. Environmental conditions such as precipitation and evapotranspiration were clustered with hydraulic heads to show that they also influence salinity concentration in groundwater [7]. In some place, seawater intrusion affects groundwater salinity in particular season. For example, Rabbani et al. confirmed that saline water starts to penetrate inland during winter months [12]. It is necessary to know the seasonal variations in groundwater salinity.

Groundwater plays a crucial role in the socioeconomic development of Jiangsu coastal plain, a developed area in eastern China. In this place, shallow groundwater is easily affected by environment, such as climate change, river stage, and Yellow Sea tidal level. With a growing population, Jiangsu faces an increasing demand for freshwater. For solving this problem, deeply understanding the groundwater system and its influencing factors is necessary. Then, the relationships among the groundwater level and climate factors, river stage, Yellow Sea tide level, and variations in groundwater salinity in this area have not been studied.

Thus, the purpose of this present study was to investigate the seasonal variations of groundwater level and salinity in Jiangsu coastal plain. Specific objectives were (1) to detect the dynamics of groundwater level and salinity in wet and dry season; (2) to determine the relationships among the groundwater level, salinity content, climate factors (precipitation and evaporation), river stage, and Yellow Sea tide level. This study can provide a management method for coastal plain groundwater by analyzing the factors that influence the groundwater level and the changing trends of groundwater salinity.

\section{Materials and Methods}

2.1. Study Site Description. Observational data on the groundwater level and salinity in Dongtai $\left(120^{\circ} 07^{\prime} \sim 120^{\circ} 53^{\prime} \mathrm{E}\right.$ and $32^{\circ} 33^{\prime} \sim 32^{\circ} 57^{\prime} \mathrm{N}$ ), Jiangsu in eastern China were collected and investigated (Figure 1). Jiangsu coastal plain lies to the west of the Yellow Sea at an altitude ranging from $2.6 \mathrm{~m}$ to $4.6 \mathrm{~m}$ above sea level. Dongtai city is in the east of Jiangsu province and adjacent to the Yellow Sea. The plain sandy area has a highly permeable soil that consists of mealy sand and extremely fine sand particles. The phreatic surface is at a shallow depth, generally $1 \mathrm{~m}$ to $3 \mathrm{~m}$, and even $0.2 \mathrm{~m}$ after rainfall below the ground surface. The average annual temperature, average annual rainfall, and evaporation rate are approximately $15.0^{\circ} \mathrm{C}, 1059.8 \mathrm{~mm}$, and $1006.7 \mathrm{~mm}$, respectively. During the study period in 2013, the annual mean precipitation was approximately $859 \mathrm{~mm}$. The maximum precipitation is recorded in July before gradually decreasing. The annual evaporation is approximately $651.5 \mathrm{~mm}$. Over $50 \%$ of the rainfall falls between July and October. Most rainfall in the summer is in the form of local showers and thunderstorms, and in winter the rainfall amount is small.

Considering that most rainfall falls between July and October and very small amount of rainfall falls between November and December in this place, July to October is recognized as the wet season and November to December is the dry season.

2.2. Experiment Design. A farmland covering an area of $50 \mathrm{~m}$ $\times 100 \mathrm{~m}$ was selected as a typical saline groundwater site with a shallow water table to study the water and salt dynamics during different seasons. The farmland was bulldozed by machine to make sure the land is flat and there is no vegetation in the farmland. The farmland is approximately $5 \mathrm{~km}$ away from the Yellow Sea and $2 \mathrm{~km}$ away from Liangduo River. Nine shallow monitoring wells were constructed and installed to a depth of $5 \mathrm{~m}$ in the aquifer of the farmland (Figure 2).

Data on daily precipitation, evaporation, river stage, and the Yellow Sea tide level were gathered from the Liangduo River dam monitoring point of Jiangsu Province Hydrology and Water Resources Investigation Bureau, which is located around $1.5 \mathrm{~km}$ northeast of the farmland. Precipitation data were collected using a rain gauge and evaporation was measured using an E601 evaporation pan. Mean daily river stage and survey of tide data were recorded manually and automatically using a groundwater level monitoring system at Liangduo River dam. The recorded groundwater levels were based on the 1985 Yellow Sea elevation. All data were collected from July 1, 2013, to December 31, 2013.

Manual monitoring logger was set to observe the groundwater table and groundwater samples collected daily from the nine wells spread in the area. The recorded water levels are below the 1985 height of the Yellow Sea. Each sample of $100 \mathrm{~mL}$ was collected from the upper monitor well. Daily groundwater level and salinity from all wells were monitored manually and analyzed. The groundwater level of nine wells had the same trend. The average value of the daily groundwater level and salinity of nine wells were obtained from July 1 , 2013, to December 31,2013. The salinity value was calibrated under $25^{\circ} \mathrm{C}$.

\section{Results}

3.1. Variations in Groundwater Level. The average depth of groundwater in the study area was $1.7 \mathrm{~m}$. In the daily groundwater fluctuation figure, the shallowest groundwater level and the deepest groundwater level were identified. The 


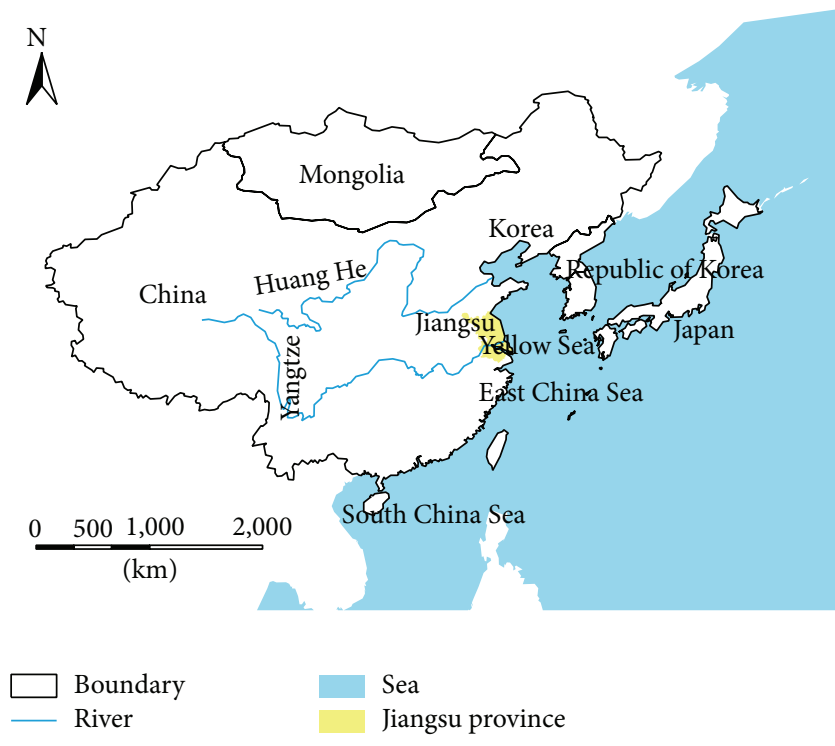

(a)

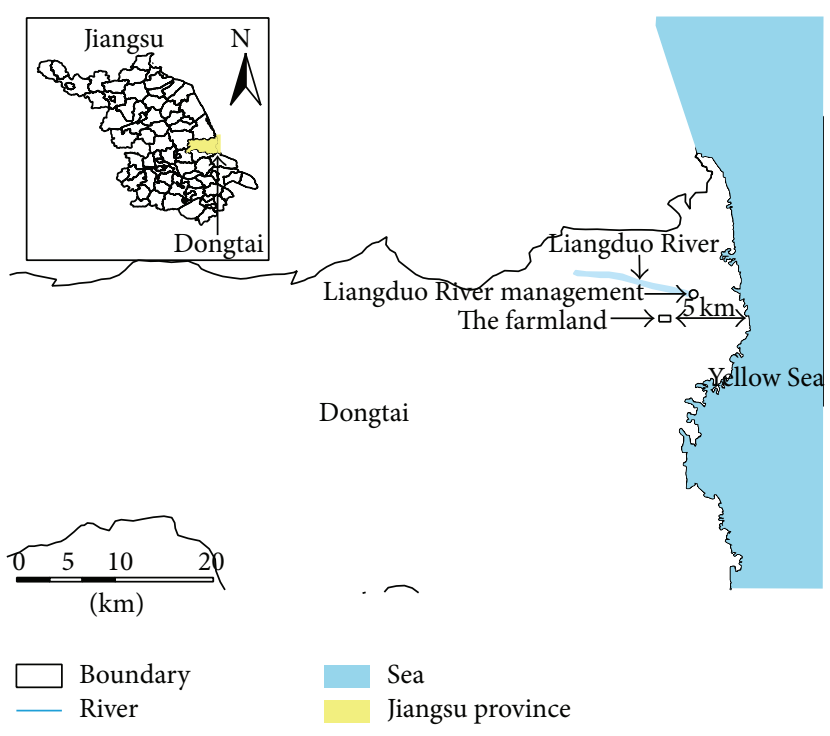

(b)

Figure 1: Geographical location of the study area. (a) Jiangsu province in China, (b) Dongtai city of Jiangsu province and the farmland.

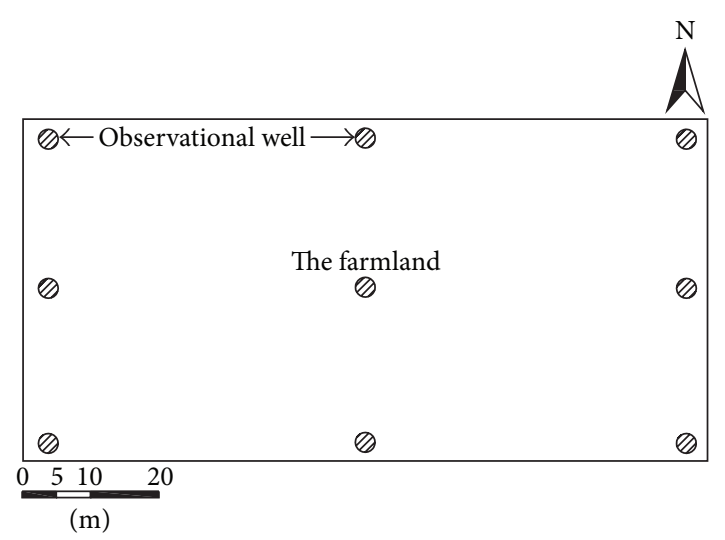

FIGURE 2: Distribution of the observation wells.

first situation corresponded to one of the shallowest water levels (on October 8) and the other to the deepest one on August 24 (Figure 3). The shallowest and deepest water levels were $24 \mathrm{~cm}$ and $254 \mathrm{~cm}$, respectively.

The main factors that affected groundwater interaction were the climate parameters (rainfall and evaporation demand) [13]. Precipitation infiltration was a key recharge source of shallow groundwater as well as the major recharge source of groundwater [14]. We observed that the groundwater level exhibited multipeak and multivalley curves and the fluctuation cycle of groundwater synchronized with precipitation events (Figure 3(a)). During the wet season, frequent and sufficient rainfall led to large fluctuations in groundwater level and the shallowest water level was reached. As indicated in Figure 3(a), the fluctuation range related to rainfall peaked at $188 \mathrm{~cm}$ after heavy rain with $74.4 \mathrm{~cm}$ precipitation on August 24 and a day of precipitation infiltration. During the dry season, the groundwater level fluctuated within a narrow range with low precipitation. During a nonrainfall period, the groundwater level exhibited a linear downward trend because of evaporation and then increased until the next precipitation occurred (Figures 3(a) and 3(b)). The period from August 1 to 19 is characterized by absence of rainfall, together with elevated temperatures and potential evapotranspiration; the longest nonrainfall period during the wet season occurred. During this period, the groundwater level reduced by $175 \mathrm{~cm}$. The groundwater level increased after the precipitation events and then decreased gradually with evaporation. The groundwater tables varied within the period from wet to dry seasons and showed seasonal variations because of the seasonal distribution of precipitation and evaporation.

In the condition of wake evaporation in December, downward trend of groundwater level was not obvious and even the level on December 31 was $3 \mathrm{~cm}$ shallower than December 1. The groundwater level in December declined initially and then increased without rainfall recharge which meant that except rainfall there were also other factors that affected groundwater level. The nearby Liangduo River or the Yellow Sea may have had an effect on the fluctuation without precipitation events.

Linear regression analysis was performed to investigate the relationships among precipitation, evaporation, river stage, sea tide level, and groundwater level. The method was used to identify the effective factors on groundwater level (Figure 4 ). In this method, $R^{2}$ values were analyzed and the $R^{2}$ values indicated correlations between groundwater level and the influence factors. The $R^{2}$ values among precipitation, evaporation, river stage, sea tide level, and groundwater level ranged from 0.004 to 0.824 . The output showed that precipitation, evaporation, and river stage were 


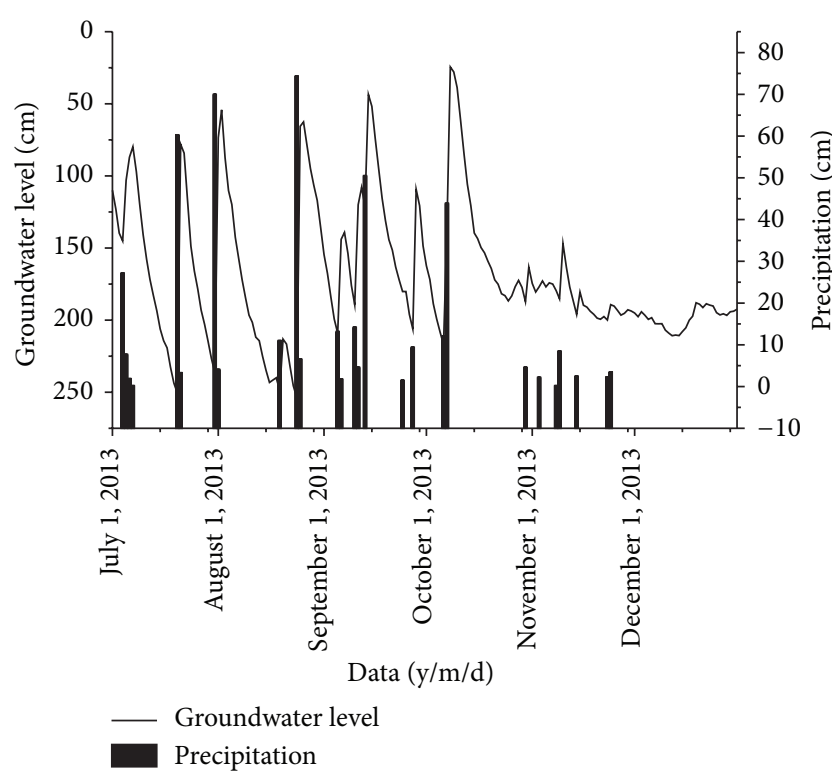

(a)

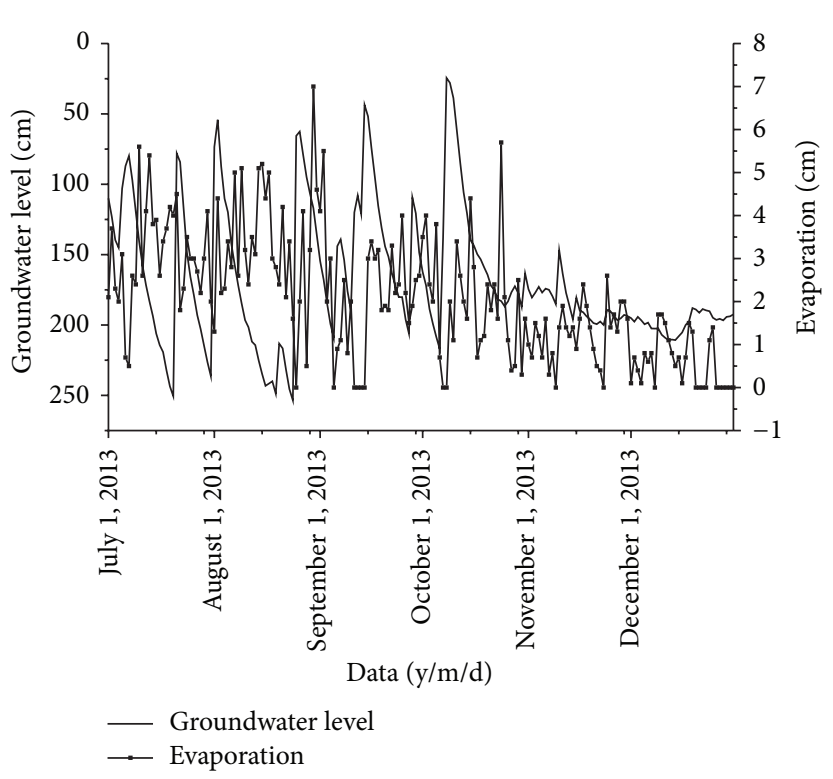

(b)

FIGURE 3: Groundwater fluctuation with precipitation and evaporation data from July 1 to December 31, 2013.

significant $(P<0.01)$ effective on groundwater level in the study area. The fitting curve showed positive correlations among groundwater level, precipitation, and river stage, as well as a negative correlation between groundwater level and evaporation. Estimating a dependent variable, which is precipitation, largely contributed to obtaining groundwater level with the highest $R^{2}$ value. The order of the influencing factors on groundwater level was precipitation $>$ river stage $>$ evaporation. The sea tide level did not affect the groundwater level $(P>0.05)$.

The result indicates that precipitation mainly drives dynamic changes in groundwater level in this study area. The groundwater level exhibited multipeak curves and a shallower water level during the wet season than during the dry season because of frequent precipitation events. During the dry season without rainfall, the groundwater level fluctuated because of fluctuations in the Liangduo River stage. River stage had effect on groundwater level. The tide level of the Yellow Sea had no influence on the groundwater level.

3.2. Variations in Groundwater Salinity. Groundwater salinity was generally affected by precipitation. The statistical values of precipitation and groundwater salinity are listed in Table 1, and the results are presented in Figure 5.

The salinity data curve can be divided into two parts. Part I showed the data curve from July to October (wet season), wherein the groundwater salinity fluctuated according to precipitating events. The groundwater salinity was reduced after precipitation events, and then began to increase gradually until the next event. Small increases of salinity during major rainfall intervals in Figure 5 may suggest that evaporation fails to accumulate salinity due to rainfall washout. The fluctuation in the groundwater salinity could be related to precipitation events. Part II showed the data curve from
November to December (dry season), wherein the amount of rainfall was lower than that during the wet season. The groundwater salinity showed increasing trends in early November and then sharply increased in late November. The groundwater salinity increased with time and reached its maximum level $(24.45 \mathrm{~g} / \mathrm{kg})$ in December.

Table 1 shows that the groundwater salinity increased as monthly precipitation decreased. In July, with abundant precipitation, the groundwater salinity was only $0.87 \mathrm{~g} / \mathrm{kg}$, the lowest salinity level in the study time series. The groundwater salinity increased each month until the maximum monthly average was reached in December. The groundwater salinity in December was approximately 23 times higher than that in July.

Table 2 shows the 27 precipitation events that occurred during the study series. Changing percentage is a ratio which is the differential value between groundwater salinity before and after rainfall divided by groundwater salinity before rainfall. The $R^{2}$ value between precipitation and changing percentage of groundwater salinity is 0.653 , which is significant at the 0.01 level. Precipitation influenced salt dilution in groundwater. A sufficient amount of rainfall diluted salt in groundwater and decreased the groundwater salinity. Inadequate rainfall had no effect on decreasing the groundwater salinity. The highest rainfall of $74.4 \mathrm{~cm}$ did not cause a high percentage of change. The highest change percentage of groundwater salinity was caused by a $60.3 \mathrm{~cm}$ precipitation event, and the $3.3 \mathrm{~cm}$ precipitation event the next day resulted in a 45.22 change percentage. The changing percentage was related not only to rainfall but also to groundwater level and the initial value of groundwater salinity. The individual and small amount of rainfall had minimal or no effect on decreasing the groundwater salinity, particularly during the dry season. Rainfalls were all less than $8.5 \mathrm{~cm}$ during the 


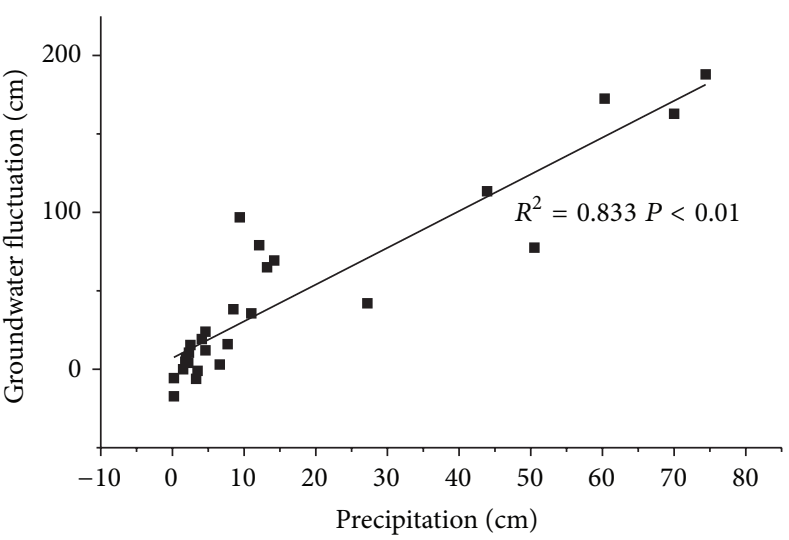

(a)

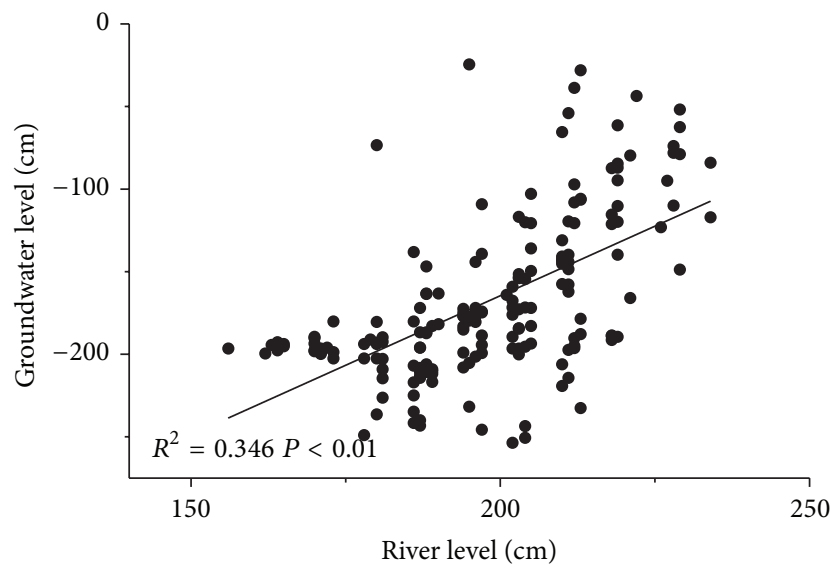

(c)

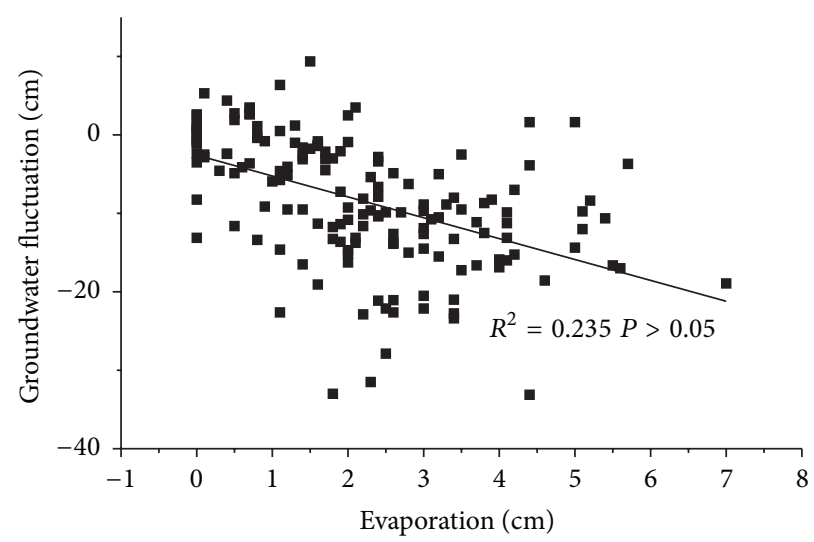

(b)

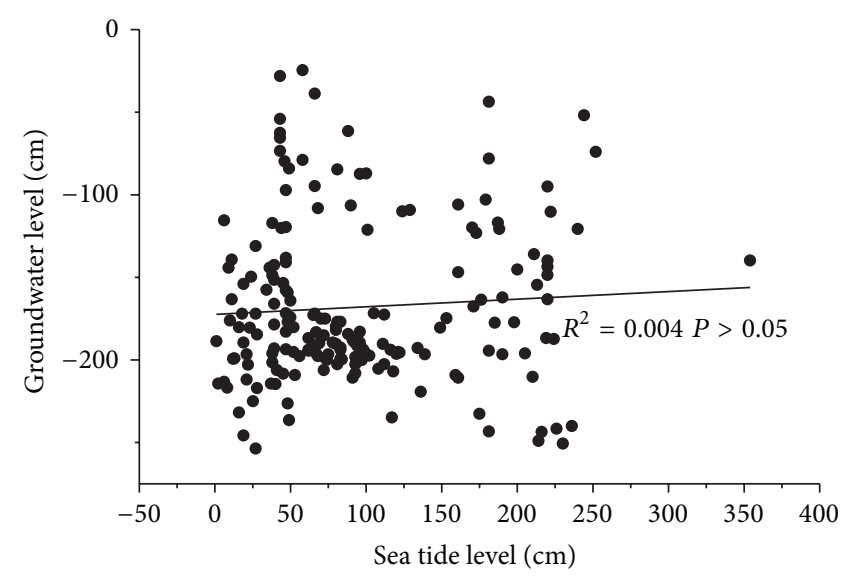

(d)

FIGURE 4: Linear regressions among precipitation, evaporation, river stage, sea tide level, and groundwater level.

TABLE 1: Monthly precipitation and evaporation and monthly average groundwater salinity and level, seasonal precipitation and evaporation, and average of groundwater salinity and level.

\begin{tabular}{|c|c|c|c|c|c|c|c|c|}
\hline & & \multicolumn{4}{|c|}{ Wet season } & \multicolumn{2}{|c|}{ Dry season } & \multirow{2}{*}{ Standard variance } \\
\hline & & July & August & September & October & November & December & \\
\hline \multirow{2}{*}{ Precipitation $(\mathrm{cm})$} & Monthly & 170.6 & 85.1 & 95.2 & 60.6 & 19.2 & 0 & 60.88 \\
\hline & Sum & & & 411.5 & & \multicolumn{2}{|c|}{19.2} & \\
\hline \multirow{2}{*}{ Evaporation $(\mathrm{cm})$} & Monthly & 94.8 & 101.9 & 62.6 & 61.7 & 37.7 & 17.6 & 32.33 \\
\hline & Sum & & & 321 & & \multicolumn{2}{|c|}{55.3} & \\
\hline \multirow{2}{*}{ Groundwater salinity $(\mathrm{g} / \mathrm{kg})$} & Monthly & 0.87 & 1.20 & 1.69 & 2.12 & 4.59 & 19.7 & 7.31 \\
\hline & Average & & & 1.47 & & \multicolumn{2}{|c|}{12.15} & \\
\hline \multirow{2}{*}{ Groundwater level $(\mathrm{cm})$} & Monthly & 163.3 & 167.1 & 145.0 & 148.9 & 185.5 & 198.3 & 20.69 \\
\hline & Average & & & 156.17 & & \multicolumn{2}{|c|}{191.99} & \\
\hline
\end{tabular}

dry season and no rainfall recharged the groundwater in December; groundwater salinity increased. The groundwater salinity sharply increased during the dry season, when no precipitation event occurred.

\subsection{Variations in Groundwater Salinity with Groundwater} Level. As analyzed in the preceding sections, rainfall caused the groundwater level and salinity to fluctuate, and groundwater salinity was low when the amount of rainfall was large. After the decreasing of groundwater salinity caused by rainfall, between two continuous precipitation events, groundwater salinity increased with the lowering of water levels. Our findings suggest that salt movement is closely related to the groundwater table.

In different seasons, the groundwater salinity exhibited different trends as the groundwater level changed, as shown in Figure 6. Praveena et al. indicated that high evaporation in areas with shallow groundwater tables may also lead to 
TABLE 2: Changing percentage of groundwater salinity according to precipitation.

\begin{tabular}{|c|c|c|c|c|c|}
\hline \multicolumn{4}{|c|}{ Wet season } & \multicolumn{2}{|c|}{ Dry season } \\
\hline $\begin{array}{l}\text { Precipitation } \\
(\mathrm{cm})\end{array}$ & $\begin{array}{l}\text { Changing percentage } \\
(\%)\end{array}$ & $\begin{array}{l}\text { Precipitation } \\
(\mathrm{cm})\end{array}$ & $\begin{array}{c}\text { Changing percentage } \\
(\%)\end{array}$ & $\begin{array}{l}\text { Precipitation } \\
(\mathrm{cm})\end{array}$ & $\begin{array}{c}\text { Changing percentage } \\
(\%)\end{array}$ \\
\hline 27.2 & -63.08 & 13.2 & -22.22 & 2.2 & +3.74 \\
\hline 7.7 & -21.11 & 1.8 & +6.59 & 0.2 & -1.31 \\
\hline 1.9 & +31.85 & 14.2 & +3.29 & 8.5 & +1.98 \\
\hline 0.2 & +11.59 & 4.6 & +2.81 & 2.5 & -2.47 \\
\hline 60.3 & -77.67 & 50.5 & -76.31 & 2.3 & +25.06 \\
\hline 3.3 & -45.22 & 1.5 & +1.42 & 3.5 & +17.80 \\
\hline 70 & -48.93 & 9.4 & -5.39 & & \\
\hline 4.1 & -14.22 & 12.1 & +2.89 & & \\
\hline 11 & -27.92 & 43.9 & -62.73 & & \\
\hline 74.4 & -59.99 & 4.6 & -2.79 & & \\
\hline 6.6 & -3.31 & & & & \\
\hline
\end{tabular}

+ means groundwater salinity increasing percentage; - means groundwater salinity decreasing percentage.

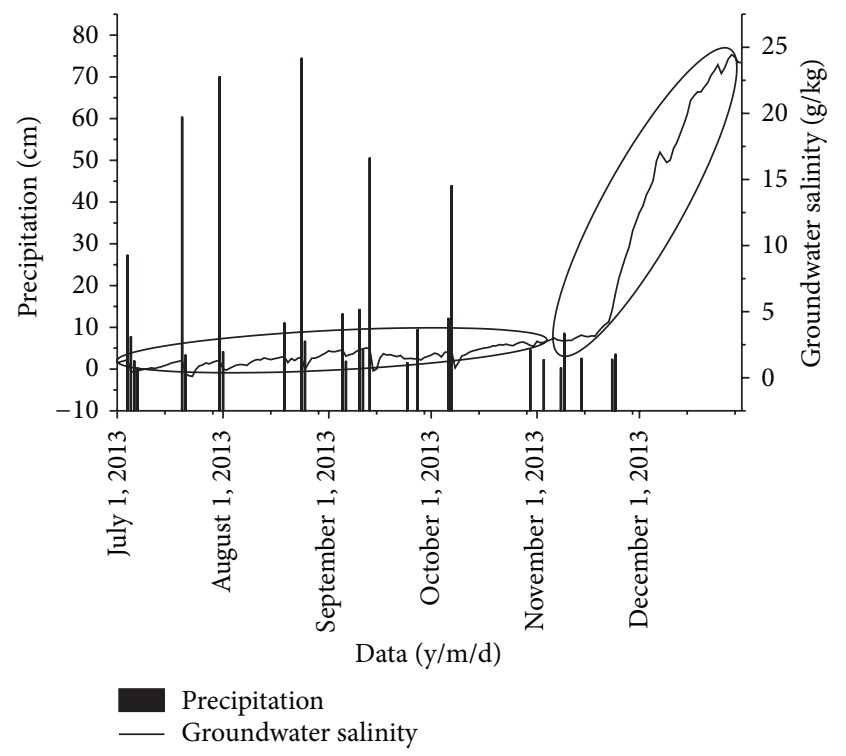

FIGURE 5: Variations in groundwater salinity and precipitation from July 1 to December 31, 2013.

salinization [7]. During the wet season, with high precipitation and evaporation, the groundwater level fluctuated frequently in a wide range and the groundwater salinity fluctuated synchronously with the groundwater level, but the trend appeared inversely.

During the observation period, the correlation coefficient between the groundwater level and salinity was 0.324 and was significantly correlated at the 0.01 level. The correlation coefficients from wet to dry seasons were 0.259 and 0.529 , respectively, and both were significantly correlated at the 0.01 level. This finding suggested that the groundwater salinity is associated with the groundwater level. The correlation coefficient during the wet season was lower than that during the dry season. Without the influence of precipitation events, a higher correlation between groundwater salinity and level was observed.

From November to December, the total rainfall was only $19.2 \mathrm{~cm}$, which occurred in early November. These precipitation events resulted in small groundwater level fluctuations (Figure 6). The groundwater salinity curve did not exhibit any noticeable fluctuation, suggesting that the small amount of rainfall did not affect the groundwater salinity. After the precipitation events, the groundwater table remained relatively stable. The groundwater level fluctuation interval was $172 \mathrm{~cm}$ to $210 \mathrm{~cm}$. During this nonrainfall period, the variations in groundwater salinity were not similar to those at the groundwater level. The groundwater salinity increased suddenly in late November before entering a period of sustained and rapid growth. Linear fits were conducted on groundwater salinity in early November and from late November to December. The linear fit equations were $y=$ $0.029 x+2.649$ and $y=0.528 x+3.991$, respectively. The growth rates of salinity were compared, with the latter period showing higher levels than the former. Without precipitation dilution, shallow groundwater salinity increased continuously during the dry season.

\section{Discussion}

The precipitation, evaporation, and groundwater level values are reported in Table 1. The time series shows that the wet season precipitation is significantly higher than that during the dry season, accounting for 95 percent of total precipitation. The evaporation and groundwater levels in the wet season are 5 times and $35 \mathrm{~cm}$ higher than those in the dry season, respectively.

4.1. Effects of Precipitation, River Stage, and Evaporation on Dynamics of Groundwater Level. The dynamics of groundwater level in the study area are affected mainly by precipitation, water level of nearby river, and evaporation. It was affected 


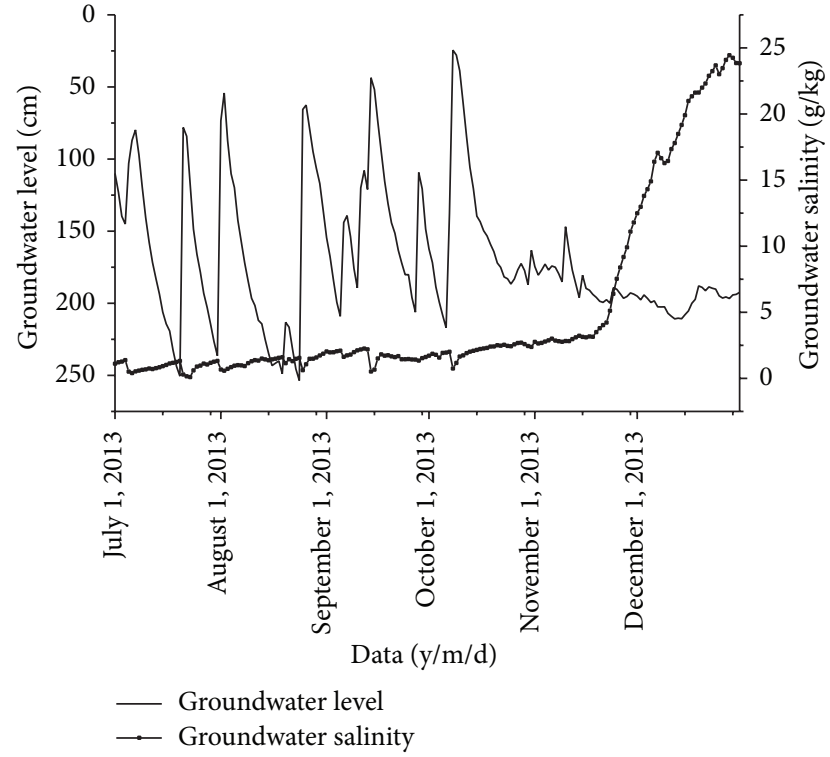

FIGURE 6: Variations in groundwater salinity with groundwater level fluctuation.

by precipitation, evaporation, and river stage. Dogan et al., Apaydin, Jan et al., Hong and Wan, and Carretero and Kruse found that precipitation was one of the dominant factors that contributed to groundwater level fluctuation [13, 15-18]. In our study, the groundwater levels quickly changed following each precipitation event. After rainfall, the groundwater level presented a linear downward trend because of evaporation until the next precipitation event occurred. The groundwater level was affected not only by precipitation and evaporation but also by the river stage.

\subsection{Effects of Precipitation Dilution on Dynamics of Ground-} water Salinity. The groundwater salinity can be reduced after the recharge of precipitation events. Research showed that the groundwater salinity changes according to precipitation events. Wang et al. pointed out that the precipitation infiltrated and leached downward to recharge groundwater, which could refresh and dilute the salt of the soil water or groundwater during the rainy season [6]. Wang et al. observed that, during dry seasons, shallow groundwater would be sanitized because of the evaporation and condensation effects in the north China plain [6]. Rabbani et al. confirmed that saline water starts to penetrate inland during winter months when river flow is low and groundwater level decreases as a result of climate change in Bangladesh [12]. These studies indicated that the shallow groundwater salinity would increase by evaporation in the condition of no precipitation or saline water penetrating. In our study, high precipitation decreased the salinity concentration in groundwater during the wet season, and continues evaporation increase salinity dramatically during the dry season. The amount of precipitation serves an important function in salt dilution. Taking advantage of precipitation can be a good method to control groundwater salinity in a coastal plain.
4.3. Variations in Groundwater Level Influence on Groundwater Salinity. According to the entire study time series, groundwater salinity changed according to the fluctuation of groundwater level. During the dry season, the correlation coefficient between the groundwater level and salinity was higher than that during the wet season. The fluctuations of groundwater level were mainly caused by precipitation and evaporation in wet season, while in dry season the groundwater level was mainly affected by the water level of Liangduo River and groundwater salinity concentration was increased sharply by seawater intrusion. Zhou et al. found that the saltwater intrusion is mainly controlled by river discharge and tidal current in Zhujiang River Estuary [19]. It is also related to wind amplitude and direction and sea level rising. A deep mechanism of saltwater intrusion should be investigated. For a clearer mechanism of saltwater intrusion in this study area, not only climate factors but also more influencing factors as above can be researched. And spatial analysis should be focused on.

\section{Conclusions}

In coastal plain of eastern China, the average depth of groundwater level is shallow and easily affected by climate factors (precipitation and evaporation) and river stage. The influencing factors on the groundwater level were in the order precipitation $>$ river stage $>$ evaporation. The groundwater salinity is influenced by climate factors, groundwater level, and seawater intrusion. Precipitation infiltrated into groundwater and diluted the salinity, so the groundwater salinity fluctuated with precipitation events. Between two precipitation events, groundwater salinity increased with evaporation. Groundwater salinity changed with the fluctuation of groundwater level and significant correlation was found between them $(P<0.01)$. In the study period, the groundwater salinity fluctuated frequently. During wet season it maintained in a low salinity level. It increased continuously and reached a maximum value in December during the dry season. The result indicated that seawater intrusion occurred in the coastal plain in dry season.

\section{Conflict of Interests}

The authors declare that there is no conflict of interests regarding the publication of this paper.

\section{Acknowledgments}

This study was financially supported by the Public Welfare Industry Special Funds for Scientific Research Projects of the Ministry of Water Resources (Grant no. 200801025) and the Innovative Project of Scientific Research for Postgraduates in Ordinary Universities in Jiangsu Province (Grant no. CXZZ13_0267). The authors thank Jiangsu Province Hydrology and Water Resources Investigation Bureau for providing them with climate data. 


\section{References}

[1] P. Kumar, M. Tsujimura, T. Nakano, and T. Minoru, “Time series analysis for the estimation of tidal fluctuation effect on different aquifers in a small coastal area of Saijo plain, Ehime prefecture, Japan," Environmental Geochemistry and Health, vol. 35, no. 2, pp. 239-250, 2013.

[2] M. A. T. M. T. Rahman, R. K. Majumder, S. H. Rahman, and M. A. Halim, "Sources of deep groundwater salinity in the southwestern zone of Bangladesh," Environmental Earth Sciences, vol. 63, no. 2, pp. 363-373, 2011.

[3] Y. Iwasaki, M. Ozaki, K. Nakamura, H. Horino, and S. Kawashima, "Relationship between increment of groundwater level at the beginning of irrigation period and paddy filed area in the Tedori River Alluvial Fan Area, Japan," Paddy and Water Environment, vol. 11, no. 1-4, pp. 551-558, 2013.

[4] Z. Chen, S. E. Grasby, and K. G. Osadetz, "Relation between climate variability and groundwater levels in the upper carbonate aquifer, southern Manitoba, Canada," Journal of Hydrology, vol. 290, no. 1-2, pp. 43-62, 2004.

[5] Z. Chen, S. E. Grasby, and K. G. Osadetz, "Predicting average annual groundwater levels from climatic variables: an empirical model," Journal of Hydrology, vol. 260, no. 1-4, pp. 102-117, 2002.

[6] S. Wang, X. Song, Q. Wang et al., "Shallow groundwater dynamics and origin of salinity at two sites in salinated and waterdeficient region of North China Plain, China," Environmental Earth Sciences, vol. 66, no. 3, pp. 729-739, 2012.

[7] S. M. Praveena, M. H. Abdullah, K. Bidin, and A. Z. Aris, "Understanding of groundwater salinity using statistical modeling in a small tropical island, East Malaysia," Environmentalist, vol. 31, no. 3, pp. 279-287, 2011.

[8] D. Liu, X. Chen, and Z. Lou, "A model for the optimal allocation of water resources in a saltwater intrusion area: a case study in pearl river delta in China," Water Resources Management, vol. 24, no. 1, pp. 63-81, 2010.

[9] Z. Li, C. Zhang, and W. Zhu, "The present and analysis of the sea water intrusion in coastland of Rizhao," Hydrogeology and Engineering Geology, vol. 36, no. 5, pp. 129-132, 2009 (Chinese).

[10] J. G. Redwood, Pump/Recharge Rate Affects Saltwater Intrusion, 2004, http://www.solinst.com/resources/papers/101c4salt.php.

[11] G. H. P. Oude Essink, "Salt water intrusion in a threedimensional groundwater system in the Netherlands: a numerical study," Transport in Porous Media, vol. 43, no. 1, pp. 137-158, 2001.

[12] G. Rabbani, A. A. Rahman, and N. Islam, "Climate change and sea level rise: issues and challenges for coastal communities in the Indian Ocean Region," in Coastal Zones and Climate Change, D. Michel and A. Pandya, Eds., pp. 17-30, The Henry L. Stimson Center, Washington, DC, USA, 2010.

[13] A. Dogan, H. Demirpence, and M. Cobaner, "Prediction of groundwater levels from lake levels and climate data using ANN approach," Water SA, vol. 34, no. 2, pp. 199-208, 2008.

[14] Q. Yong, Z. Zhang, Y. Fei et al., "Calculating precipitation recharge to groundwater applying envieronmental chloride tracer method," in Proceedings of the International Symposium on Water Resource and Environmental Protection (ISWREP '11), vol. 1, pp. 139-143, Xi’an, China, May 2011.

[15] A. Apaydin, "Response of groundwater to climate variation: fluctuations of groundwater level and well yields in the Halacli aquifer (Cankiri, Turkey)," Environmental Monitoring and Assessment, vol. 165, no. 1-4, pp. 653-663, 2010.
[16] C.-D. Jan, T.-H. Chen, and H.-M. Huang, "Analysis of rainfallinduced quick groundwater-level response by using a Kernel function," Paddy and Water Environment, vol. 11, no. 1-4, pp. 135-144, 2013.

[17] Y.-M. Hong and S. Wan, "Forecasting groundwater level fluctuations for rainfall-induced landslide," Natural Hazards, vol. 57, no. 2, pp. 167-184, 2011.

[18] S. C. Carretero and E. E. Kruse, "Relationship between precipitation and water-table fluctuation in a coastal dune aquifer: Northeastern coast of the Buenos Aires province, Argentina," Hydrogeology Journal, vol. 20, no. 8, pp. 1613-1621, 2012.

[19] W. Zhou, D. Wang, and L. Luo, "Investigation of saltwater intrusion and salinity stratification in winter of 2007/2008 in the Zhujiang River Estuary in China," Acta Oceanologica Sinica, vol. 31, no. 3, pp. 31-46, 2012. 

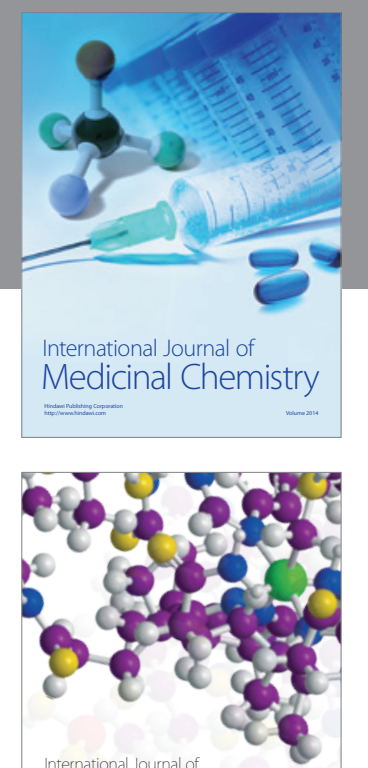

\section{Carbohydrate} Chemistry

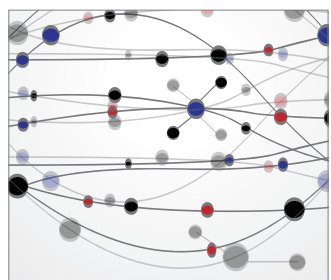

The Scientific World Journal
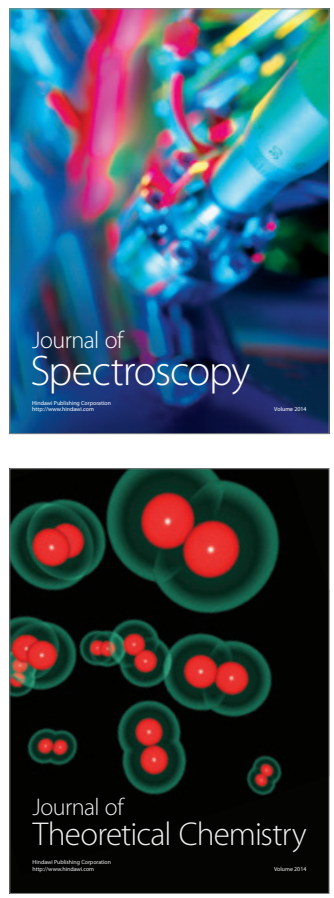
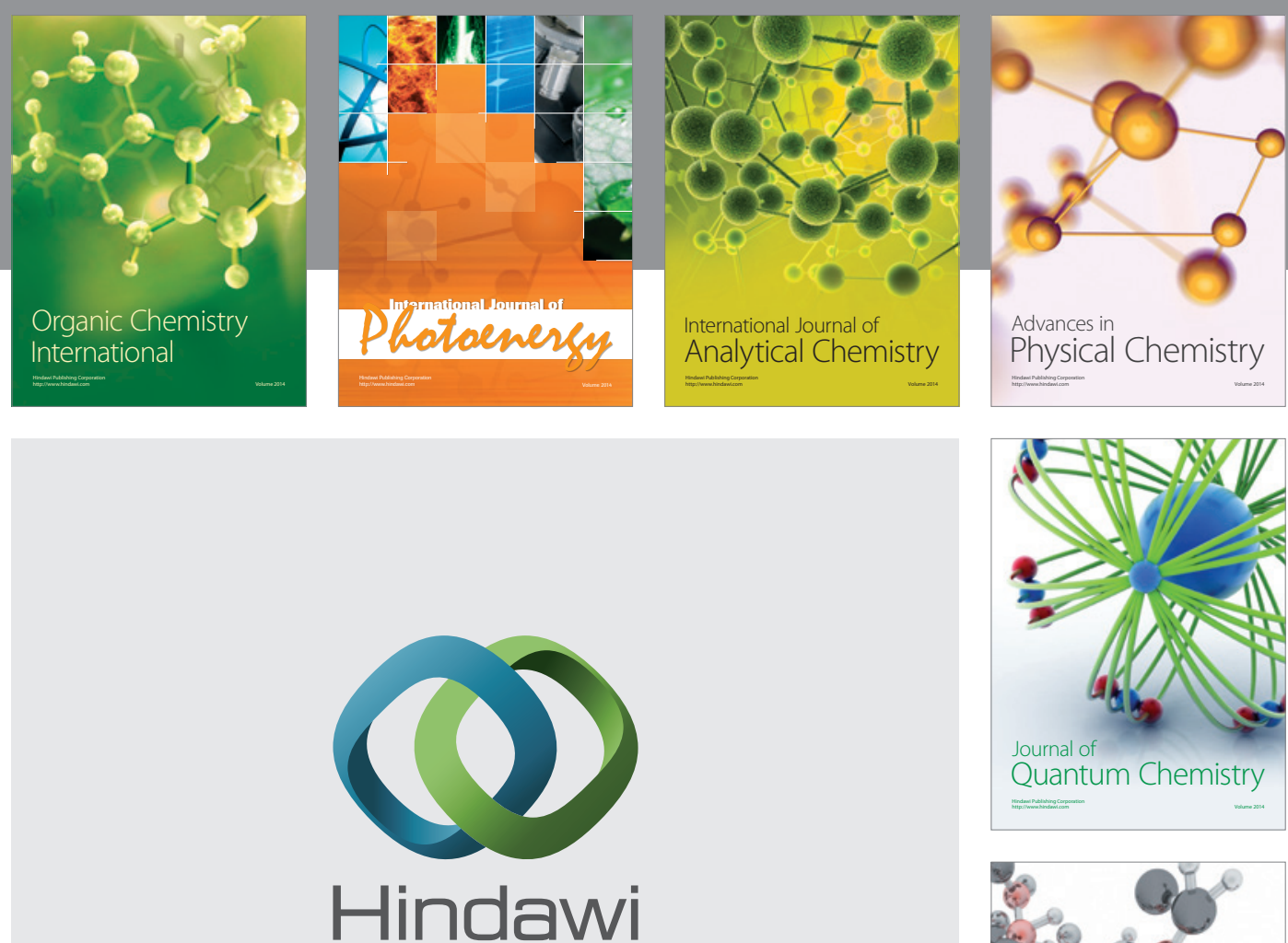

Submit your manuscripts at

http://www.hindawi.com

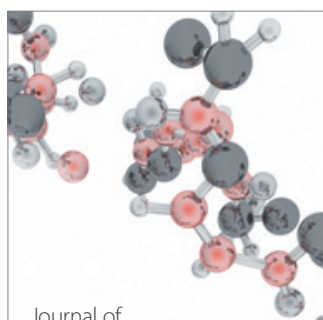

Analytical Methods

in Chemistry

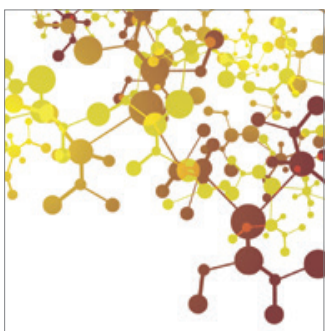

Journal of

Applied Chemistry

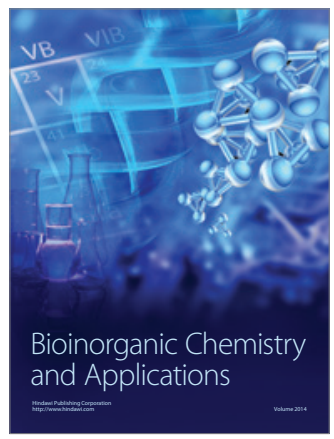

Inorganic Chemistry
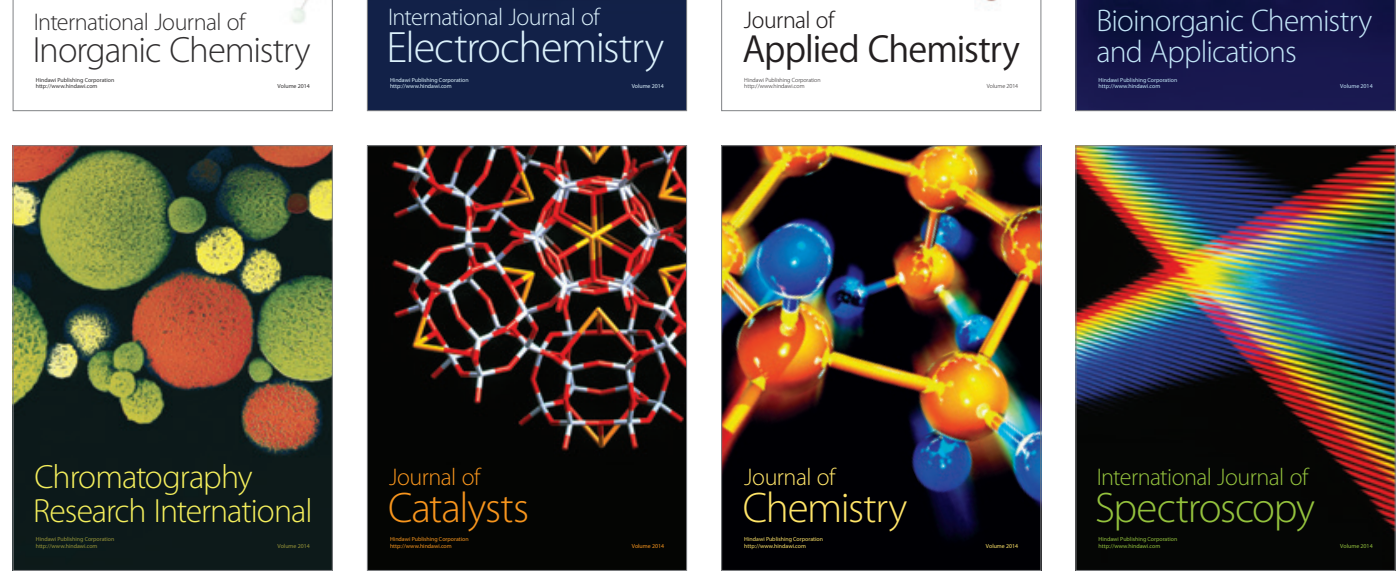